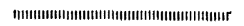 \\ 脈動流れにおける円柱および球からの物質移動に \\ 関する理論解析*
}

\author{
近江 宗 一**. 碓 井建 夫**
}

\section{Theoretical Investigation of Mass Transfer from a Cylinder and \\ a Sphere in Pulsating Flow}

\author{
Munekazu OHMI and Tateo UsuI
}

\begin{abstract}
Synopsis :
Analytical solutions of the velocity around bodies oscillating harmonically with small amplitude in a stagnant fluid are derived from the boundary-layer theory. Steady secondary flows around a circular cylinder and a sphere are calculated and shown schematically.

Generalized expressions for the local and overall mass transfer from these bodies in steady, oscillating, and pulsating flows are derived on the basis of the equation of mass balance by using the solutions mentioned above and those reported previously for steady flow. The integrals included in these expressions being evaluated numerically, the local mass-transfer distributions around bodies and the overall expressions are shown for each flow. These results are compared with the analytical and experimental ones reported previously, and shown to be rather satisfactory. The approximate expressions for pulsating flow are $S h=\left[(0.615)^{1.74}+\left(0.728 z^{1 / 3}\right)^{1.74}\right]^{1 / 1.74} S c^{1 / 3} \operatorname{Re}_{p}^{1 / 2} \quad$ (circular cylinder)

and $\quad S h=2+\left[(0.654)^{1.85}+\left(0.648 z^{1 / 3}\right)^{1.85}\right]^{1 / 1.85} S c^{1 / 3} \operatorname{Re}_{p}{ }^{1 / 2} \quad($ sphere),

where $S h=2 r_{0} k_{f} \mid D, z=\left(a \omega / U_{\infty}\right)^{3 / 2}\left(a / r_{0}\right)^{1 / 2}, S c=\nu / D$, and $R e_{p}=2 r_{0} U_{\infty} / \nu\left(a\right.$, amplitude; $D$, diffusivity; $k_{f}$, mass-transfer coefficient; $r_{0}$, radius; $U_{\infty}$, free stream velocity; $\nu$, kinematic viscosity; $\omega$, angular frequency) These expressions become ones for steady flow as $z->0$, and ones for oscillating flow as $z \rightarrow \infty$.
\end{abstract}

\section{1. 緒語}

前報1)で酸化鉄ペレット単一球の還元反応に脈動流れ を適用した場合の効果を一界面の未反応核モデル22を用 いて理論的に推定した. その際に, 脈動流れは化学反応 速度定数 $k_{c}$, 精内拡散係数 $D_{e}$ に影響老与えず，ガス境 膜内物質移動係数 $k_{f}$ のみを增大させると仮定して， $k_{c}$, $D_{e}$ には定常流れの場合の值を， $k_{f}$ には北浦ら ${ }^{3)}$ の式を 適用した、しかしこのような計算では，必ずしも十分と は言えないところがある。そこで本報では，まず酸化鉄 ペレットなどの単一試料の定常および脈動流れにおける ガス境膜内物質移動係数を再検討する目的で, 円柱およ び球からの物質移動を理諭的に解析した.

このような研究は従来より, 理論と実験の両面から, 定常流れ，変動流れおよび脈動流れなどの場合について いろいろと行なわれており，前報1)では北浦ら)の式を 用いたが，元来この式は定常流中で球が振動する実験か
ら得られた半理論的な実験式であることや，行なわれた 実験の範囲を越えて著者らの計算に用いたことなどもあ つて，再検討する必要を感じていた，本論文では，まず 一般性のある基礎的な流れの場の解析として, 静止流体 中で微小・調和振動する物体のまわりの速度を境界層理 論に基づいて導き，つぎにこの結果と定常流れの場の彷 来の解析結果とを用いて, 定常, 変動および脈動流れに 子ける円柱と球からの局所ならびに総括物質移動係数を 求めた，彷来の実験結果との比較を一部試みたが，さら に詳しい実験的検討については, 球の場合に限定して次 報で行なうことにする。

\section{2. 静止流体中で微小・調和振動する 物体のまわりの流れ}

ここではまず物体が静止流体中で微小・調和振動する 場合に生じる流れを境界層理論に基づいて導いた·良来， 面対称な柱体の場合を SCHLICHTING4) が，回転対称物

* 昭和 51 年 4 月本会講演大会にて発表 昭和 51 年 12 月 6 日受付 (Received Dec. 6, 1976)

** 大阪大学工学部 工博 (Faculty of Engineering, Osaka University, Yamada-kami Suita Osaka 565) 
体の場合を RoY5) が導いているが，後者の場合数式に 誤りが多く，検討も不十分であるので，これらの点に関 しても訂正補足を行なつた.

なお非圧縮性流体についての解析を行なつたので，静 止物体のまわりで流体が振動する場合にも適用できるこ とになる、したがつて主流が存在する場合には，その流 速は音速に比べて十分小さい場合に限定されることにな る.

\section{$2 \cdot 1$ 基礎式}

Fig. 1 に示した物体のまわりの粘性非圧縮性非定常 流れの基䃌式は， $u ， v$ をそれぞれ $x, y$ 方向の速度成 分とすると，物体近傍の境界層内部においては6)

$$
\begin{aligned}
& \frac{\partial u}{\partial t}+u \frac{\partial u}{\partial x}+v \frac{\partial u}{\partial y}=-\frac{1}{\rho} \frac{\partial p}{\partial x}+\nu \frac{\partial^{2} u}{\partial y^{2}} . \\
& \partial(u r) / \partial x+\partial(v r) / \partial y=0 \ldots \ldots \ldots \ldots \ldots \ldots \ldots \ldots \ldots \ldots \ldots \ldots \ldots \ldots \ldots
\end{aligned}
$$

また境界層外部においては

$$
-(1 / \rho) \partial p / \partial x=\partial U / \partial t+U \partial U / \partial x
$$

となり，境界層外縁で压力が等しいことから（1）式は (3)式を代入して

$$
\frac{\partial u}{\partial t}+u \frac{\partial u}{\partial x}+v \frac{\partial u}{\partial y}=\frac{\partial U}{\partial t}+U \frac{\partial U}{\partial x}+\nu \frac{\partial^{2} u}{\partial y^{2}} \cdots
$$

と表わせる. 境界条件は

$$
y=0: u=v=0, \quad y=\infty: u=U .
$$

であり， $\omega$ を角周波数として境界層外部のポテンシャル 流れをつぎのようにおく.

$$
U(x, t)=U_{0}(x) \mathrm{e}^{i \omega t}
$$

いま流れ関数 $\phi$ として次式

$u=(1 / r) \partial \phi / \partial y$, $v=-(1 / r) \partial \psi / \partial x \cdots$

を採用する・ただし Fig. 1(a)に示した面対称な奥行無 限長の物体の場合には $r=1$ としておけばよい。

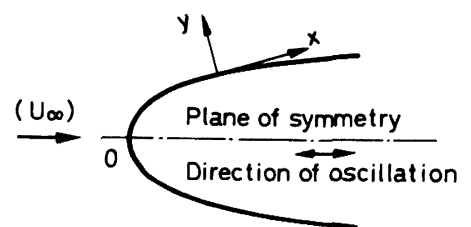

(a) Symmetrical cylinder (two-dimensional case)

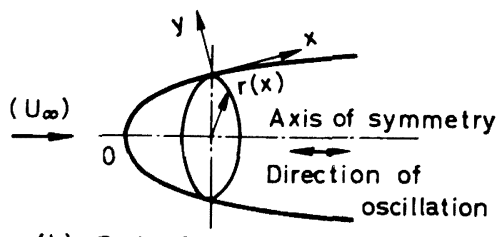

(b) Body of revolution

Fig. 1. System of co-ordinates.

\section{2 速度の近似解の誘萃}

(4)式はそのままでは解けないが，微小振動する流れ では

$$
\left.\begin{array}{l}
u(x, y, t)=u_{1}(x, y, t)+u_{2}(x, y, t) \\
v(x, y, t)=v_{1}(x, y, t)+v_{2}(x, y, t)
\end{array}\right\}
$$

ただし

$$
\begin{aligned}
& \partial u_{1} / \partial t-\nu \partial^{2} u_{1} / \partial y^{2}=\partial U / \partial t \\
& \frac{\partial u_{2}}{\partial t}-\nu \frac{\partial^{2} u_{2}}{\partial y^{2}}=U \frac{\partial U}{\partial x}-u_{1} \frac{\partial u_{1}}{\partial x}-v_{1} \frac{\partial u_{1}}{\partial y}
\end{aligned}
$$

と近似すると解析的に解ける。ここで境界条件はつぎの ようにとる.

$$
y=0: u_{1}=v_{1}=u_{2}=v_{2}=0, \quad y=\infty: u_{1}=U \cdot .
$$

いま無次元座標を $\quad \eta=y \sqrt{\omega / \nu}$ ととり, (9)式 右辺の形から流れ関数の第 1 近似 $\psi_{1}$ をつぎのように仮 定する.

$$
\phi_{1}(x, y, t)=\sqrt{\nu / \omega} U_{0}(x) r \zeta_{1}(\eta) e^{i \omega t}
$$

なお $(7)$ 式の関係より次式が得られる。

$$
\begin{aligned}
& u_{1}=U_{0}(x) \zeta_{1}^{\prime}(\eta) e^{i \omega t} \\
& v_{1}=-\sqrt{\frac{\nu}{\omega}}\left\{\frac{d U_{0}}{d x}+\frac{U_{0}}{r} \frac{d r}{d x}\right\} \zeta_{1}(\eta) e^{i \omega t}
\end{aligned}
$$

ここでプライムはりに関する微分を表わす（6)，(13)式 を(9)式に代入すると

$$
i \zeta_{1}^{\prime}-\zeta_{1}^{\prime \prime \prime}=i
$$

となり，境界条件は

$$
\eta=0: \zeta_{1}=\zeta_{1}^{\prime}=0, \quad \eta=\infty: \zeta_{1}^{\prime}=1
$$

であるからつぎのよな解を得る。

$$
\zeta_{1}=-\frac{1-i}{\sqrt{2}}+\eta+\frac{1-i}{\sqrt{2}} \mathrm{e}^{-(1+i) \eta / V \overline{2}}
$$

つぎに(10)式右辺の形から流れ関数の第 2 近似 $\psi_{2}$ を つぎのように仮定する.

$$
\begin{gathered}
\psi_{2}(x, y, t)=\sqrt{\frac{\nu}{\omega}} U_{0} \frac{d U_{0}}{d x} \frac{r}{\omega}\left\{\zeta_{2 a}(\eta) \mathrm{e}^{2 i \omega t}+\zeta_{2 b}(\eta)\right\} \\
+\sqrt{\frac{\nu}{\omega}} \frac{U_{0}^{2}}{\omega} \frac{d r}{d x}\left\{\zeta_{2 c}(\eta) \mathrm{e}^{2 i \omega t}+\zeta_{2 d}(\eta)\right\} \cdots \cdots(18)
\end{gathered}
$$

したがつて $u_{2}, v_{2}$ はつぎのように表わされる.

$$
\begin{aligned}
u_{2} & =\frac{U_{0}}{w} \frac{d U_{0}}{d x}\left(\zeta_{2 a}^{\prime} \mathrm{e}^{2 i \omega t}+\zeta_{2 b}^{\prime}\right) \\
& +\frac{U_{0}^{2}}{\omega r} \frac{d r}{d x}\left(\zeta_{2 c}^{\prime} e^{2 i \omega t}+\zeta_{2 d}^{\prime}\right) \cdots \ldots \ldots \ldots \ldots \ldots(19) \\
v_{2} & =-\frac{1}{r} \sqrt{\frac{\nu}{\omega}}\left\{\left(\frac{d U_{0}}{d x}\right)^{2} \frac{r}{\omega}+U_{0} \frac{d^{2} U_{0}}{d x^{2}} \frac{r}{\omega}\right. \\
& \left.+\frac{U_{0}}{\omega} \frac{d U_{0}}{d x} \frac{d r}{d x}\right\}\left(\zeta_{2 a} e^{2 i \omega t}+\zeta_{2 b}\right) \\
& -\frac{1}{r} \sqrt{\frac{\nu}{\omega}}\left(\frac{2 U_{0}}{\omega} \frac{d U_{0}}{d x} \frac{d r}{d x}+\frac{U_{0}^{2}}{\omega} \frac{d^{2} r}{d x^{2}}\right)\left(\zeta_{2 c} e^{2 i \omega t}+\zeta_{2 d}\right)
\end{aligned}
$$


いま $U, u_{1}, v_{1}, u_{2}$ について実部をとり，これらを(10) 式に代入すると次式を得る。

$$
\begin{aligned}
& 2 i \zeta_{2 a}^{\prime}-\zeta_{2 a}^{\prime \prime \prime}=\left(1-\zeta_{1}^{\prime 2}+\zeta_{1} \zeta_{1}^{\prime \prime}\right) / 2 \\
& \zeta_{2 b}^{\prime \prime \prime}=-1 / 2+\zeta_{1}^{\prime} \bar{\zeta}_{1}^{\prime} / 2-\left(\zeta_{1} \bar{\zeta}_{1}^{\prime \prime}+\bar{\zeta}_{1} \zeta_{1}^{\prime \prime}\right) / 4 \\
& 2 i \zeta_{2 c}^{\prime}-\zeta_{2 c}^{\prime \prime \prime}=\zeta_{1} \zeta_{1}^{\prime \prime} / 2 \\
& \zeta_{2 d}^{\prime \prime \prime}=-\left(\zeta_{1} \bar{\zeta}_{1}^{\prime \prime}+\bar{\zeta}_{1} \zeta_{1}^{\prime \prime}\right) / 4
\end{aligned}
$$

ここで一は共役複素数であり，境界条件はつぎのように とる4.

$$
\left.\begin{array}{l}
\eta=0: \zeta_{2 n}=\zeta_{2 n}^{\prime}=0 \quad(n=a, b, c, d) \\
\eta=\infty: \zeta_{2 a}^{\prime}=\zeta_{2 c}^{\prime}=0, \zeta_{2 b}^{\prime}=\text { 有限, } \zeta_{2 d}^{\prime}=\text { 有限 }
\end{array}\right\}
$$

そこでつぎのような解を得る。

$$
\begin{aligned}
& \zeta_{21}=\frac{1+i}{4} e^{-(1+i) \eta+\frac{i}{2} \eta e^{-(1+i) \eta / V} \overline{2}}-\frac{1+i}{4} . \cdots \\
& \zeta_{2} ;=-\frac{1}{4 \sqrt{2}} e^{-} \sqrt{2} \eta-\frac{3}{\sqrt{2}} e^{-r_{i} / V \overline{2}} \cos \frac{\eta}{V^{2} 2} \\
& -\sqrt{2} e^{-\eta / V} \overline{2} \sin \frac{\eta}{\sqrt{2}}-\frac{\eta}{2} e^{-\eta / V} \overline{2} \sin \frac{\eta}{\sqrt{2}} \\
& -\frac{3}{4} \eta+\frac{13}{4 \sqrt{2}} \\
& \zeta_{2 c}=-\frac{1+i}{8 \sqrt{2}} e^{-\sqrt{2}}(1+i) \eta+\frac{7}{8}(1+i) e^{-(1+i) \eta} \\
& -\frac{1+i}{\sqrt{2}} e^{-(1+i) \eta / V} \overline{2}+\frac{i}{2} \eta e^{-(1+i) \eta / V} \overline{2} \\
& -\frac{(7 \sqrt{2}-9)(1+i)}{8 \sqrt{ } 2}
\end{aligned}
$$

$\zeta_{2 d}=-\sqrt{2} e^{-\eta / V} \overline{2} \cos \frac{\eta}{\sqrt{2}}-\frac{1}{\sqrt{2}} e^{-\eta / V}=\sin \frac{\eta}{\sqrt{2}}$

$$
-\frac{\eta}{2} e^{-\eta / \nu} \overline{2} \sin \frac{\eta}{\sqrt{2}}-\frac{\eta}{2}+\sqrt{2}
$$

したがつて，これらの第 2 近似の解からつぎのような定 常二次流れ (secondary flow) が生じることがわかる.

$$
\begin{aligned}
& \left(u_{t a}\right)_{y=\infty}=\left(u_{2, t a}\right)_{y=\infty} \\
& =\frac{U_{0}}{\omega} \frac{d U_{0}}{d x}\left(\zeta_{2 b}^{\prime}\right)_{\eta=\infty}+\frac{U_{0}^{2}}{\omega r} \frac{d r}{d x}\left(\zeta_{2 d}^{\prime}\right)_{\eta=\infty} \\
& =-\frac{3}{4} \frac{U_{0}}{\omega} \frac{d U_{0}}{d x}-\frac{1}{2} \frac{U_{0}^{2}}{\omega r} \frac{d r}{d x} \ldots \ldots \ldots \ldots \ldots \ldots
\end{aligned}
$$

ここで添字 $t a$ は時間平均值を表わす。またつぎの関係 も得られる。

$$
\begin{aligned}
& \left(\frac{\partial u_{t a}}{\partial y}\right)_{y=0}=\sqrt{\frac{\omega}{\nu}} \frac{U_{0}}{\omega} \frac{d U_{0}}{d x}\left(\zeta_{2 b}^{\prime \prime}\right)_{\eta=0} \\
& +\sqrt{\frac{\omega}{\nu}} \frac{U_{0}^{2}}{\omega r}\left(\zeta_{2 d}^{\prime \prime}\right)_{\eta=0}=\frac{1}{2 \sqrt{2}} \sqrt{\frac{\omega}{\nu}} \frac{U_{0}}{\omega} \frac{d U_{0}}{d x}
\end{aligned}
$$

ところで(8)式において第 3 近似の速度成分 $u_{3}, v_{3}$ ま で考えると，(4)式から逐次近似式として次式

$$
\begin{gathered}
\partial u_{3} / \partial t-\nu \partial^{2} u_{3} / \partial y^{2}=-u_{1} \partial u_{2} / \partial x-u_{2} \partial u_{1} / \partial x \\
-v_{1} \partial u_{2} / \partial y-v_{2} \partial u_{1} / \partial y \quad \ldots \ldots \ldots \ldots \ldots \ldots \ldots \ldots \ldots \ldots \ldots \ldots \ldots \ldots \ldots
\end{gathered}
$$

が得られ，上式右辺の形から流れ関数の第 3 近似 $\psi_{3}$ は $e^{i \omega t}$ と $e^{3 i \omega t}$ の項から成ることになる. したがつて, 物 質移動過程に直接関係寸る定常二次流れには, 第 3 近似 の項は影響を及ぼさないことがわかる.なお二次元物体 の場合については， $\mathrm{SHAH}^{7}$ がこの解を求めており，第 3 近似まで考虑すると物体のまわりの変動速度の值はわ ずかに異なつてくるが本質的な差はないことを示してい る.

\section{$2 \cdot 3$ 円柱および球のまわりの二次流れ}

\section{$2 \cdot 3 \cdot 1$ 円柱の場合}

この場合のボテンシャル流れの振幅!お，振動の振幅を $a$ とすると

$$
U_{0}(x)=2 a \omega \sin \left(x / r_{0}\right)
$$

と表わされる6)ので，流れ闒数の時閪平均值はつぎのよ うになる。

$$
\begin{aligned}
\phi_{t a} & =\varphi_{2, t a}=\sqrt{\nu / \omega}\left(U_{0} / \omega\right)\left(d U_{0} / d x\right) \zeta_{2} \\
& =4 \sqrt{\nu \omega} \frac{a^{2}}{r_{0}} \sin \frac{x}{r_{0}} \cos \frac{x}{r_{0}} \zeta_{2 b} \ldots \ldots \ldots \ldots \ldots . . . . .
\end{aligned}
$$

Fig. 1(a) の場合の例として円柱のまわりの二次流れを Fig. 2 に示したが, 逆方向の二種類の定常流れが見られ る.また(34)式, Fig. 2 より $\theta=x / r_{0}$ が $90^{\circ}$ および $45^{\circ}$ に関して対称であることがわかる.なお円柱の場合の本 解析結果 [(26), (27) 式〕は SCHLichtingd) の解析結果 とまつたく同一であるが，Fig. 2 の流線四では然次元化 して一般的に示してある.このような二次流れの測定例 としては, Schlichting4), Holtsmark ら8) Bertelien ら9)の報告があり， Fig. 2 のような流れの生ずること が知られている。

HOLTSMARKら8) はより敩密な解析として Navier-

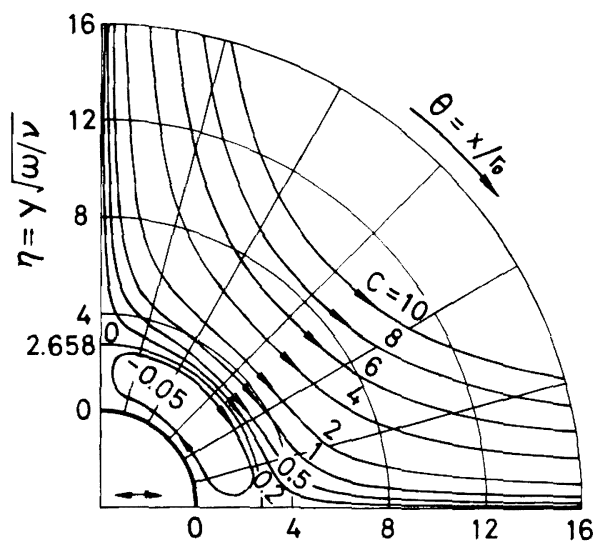

Fig. 2. Pattern of streamlines of the steady secondary motion around an oscillating circular cylinder.

$C=r_{0} \dot{\psi}_{t a} /\left(a^{2} \sqrt{\nu \omega}\right)=2 \zeta_{2 b}(\eta) \sin 2 \theta$ 
Stokes の運動方程式から出発して，逐次近似法を用い て近似解を求め，この結果がSCHLICHTING4) の解析結果 よりも実測値とよく一致することを示している。活かに も，円柱などの二次元物体のまわりの変動流れについて 多くの詳細な研究7)9) -11)が行なわれているが，物質移動 過程の解析に適した簡洣な解析解として，ここで示した 近似解を用いることにする。

\section{$2 \cdot 3 \cdot 2$ 球の場合}

この場合

$$
U_{0}(x)=\frac{3}{2} a \omega \sin \frac{x}{r_{0}}, r(x)=r_{0} \sin \frac{x}{r_{0}}
$$

と表わされる6)ので，流れ関数の時間平均值はつぎのよ うになる。

$$
\begin{aligned}
& \psi_{t a}=\sqrt{\frac{\nu}{\omega}} U_{0} \frac{d U_{0}}{d x} \frac{r}{\omega} \zeta_{2} ;+\sqrt{\nu} \frac{U_{0}^{2}}{\omega} \frac{d r}{d x} \zeta_{2 d} \\
& =\frac{9}{4} a^{2} \sqrt{\nu \omega} \sin ^{2} \frac{x}{r_{0}} \cos \frac{x}{r_{0}}-\left(\zeta_{2} b+\zeta_{2 d}\right)
\end{aligned}
$$

Fig. 1 (b) の場合の例として球のまわりの二次流れを Fig. 3 に示す. (36)式, Fig. 3 より $\theta=90^{\circ}$ に関しては 対称であるが，円柱の場合とは異なり $\theta=45^{\circ}$ に関して は対称ではない，遠藤ら ${ }^{12)} は ，$ 球の場合にもこのような 二次流れが生じることを観察している。

なお球などの回転対称物体のまわりの変動流れについ てのかなり籍密な理論解析は YEH ら ${ }^{13)}$ ，RILEY14) らが 行なつているが，先に述べた理由から，ここで示した近 似解を物質移動過程の解析に用いることにする.

\section{3. 円柱および球からの物質移動}

円柱6)，球5)15) などの物体のまわりの定常流れの速度

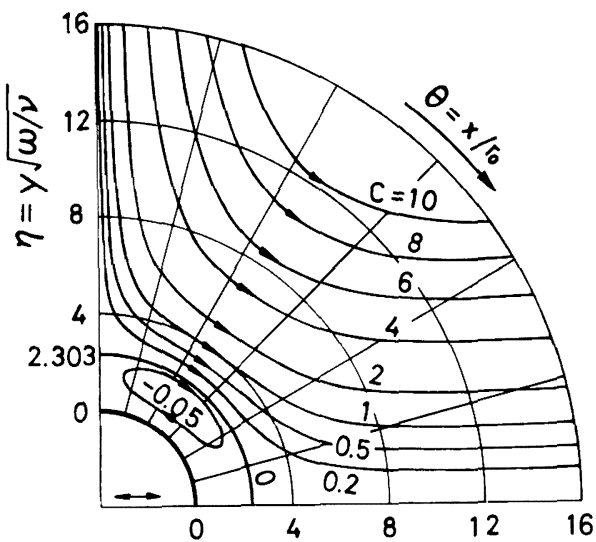

Fig. 3. Pattern of streamlines of the steady secondary motion around an oscillating sphere.

$C=\psi_{t a} /\left(a^{2} \sqrt{\nu \omega}\right)=(9 / 4)\left[\zeta_{2 b}(\eta)+\zeta_{2 d}(\eta)\right] \sin ^{2} \theta \cos \theta$
の解は Blasius 級数を拡張した形で導かれており，ま た微小・調和振動する流れの場合については 2 章で述べ たとおりである.そこで，これらの結果と，JAMESON ${ }^{16)}$ らが微小・調和振動する円柱からの物質移動を求めた解 析方法とを用いて，定常，変動および脈動流れにおける 円柱と球からの局所ならびに統括物質移動係数を，すべ て一貫した解析法のもとに導いた。 以下においては，ま ず $3 \cdot 1$ 節で, 球が静止流体中で微小・調和振動する場合 について詳しく述べ，他の場合については 3.2 節におい て，この解析内容と異なる部分を簡単に述べることにす 万.

\section{$3 \cdot 1$ 微小・調和振動する球からの物質移動}

2 章で示したとおり円柱や球などの物体が微小・調和 振動する場合, そのまわりに定常な二次流れが生じるが， このような流れによる物質移動はシュミット数が $S c \equiv$ $\nu / D \gg 1$ 時, 近似的に次式に従 $5^{16)}$.

$$
u_{t a} \partial C / \partial x=D \partial^{2} C / \partial y^{2}
$$

交た境界条件はつぎのようになる。

$$
x=0 \text { または } y=\infty: C=0, y=0: C=C_{0}
$$

(37)式に $x=r_{0} \theta$ の関係を用い，流線に沿う物質収支を とると次式を得る。

$$
u_{l a}(\partial C / \partial \theta)_{\psi}=r_{0} D\left(\partial^{2} C / \partial y^{2}\right)_{\theta}
$$

いま濃度境界層が速度境界層よりもうすい場合（Sc 》1)を考えているので，濃度境界層内の速度分布を直線 近似して

$$
u_{t a}=\beta y, \quad \beta=\left(\partial u_{t a} / \partial y\right)_{y=0} \cdots
$$

とおくと, $\beta$ は(31)式と(35)式から

$$
\beta=9 a^{2} \omega^{3 / 2} \sin 2 \theta /\left(2^{9 / 2} r_{0} \nu^{1 / 2}\right) \cdots
$$

となり，流れ関数は(7)式と(40)式から

$$
\varphi=\int_{0}^{y} u_{t a} r d y=\frac{1}{2} \beta r_{0} y^{2} \sin \theta
$$

となる。

いますべての物質移動の行なわれる仮想の境界層厚さ を」とすると

$$
\left.\left.\psi_{\lrcorner}=(1 / 2) \beta r_{0}\right\lrcorner^{2} \sin \theta, \quad \phi=\psi_{\lrcorner} Y^{2}, \quad Y=y /\right\lrcorner \cdots
$$

となるので $\phi=$ const. ならば $Y$ も定となつて (39) 式 はつぎのように書ける.

$$
Y(\partial C / \partial \theta)_{Y}=\left[r_{0} D /\left(\beta \Delta^{3}\right)\right]\left(\partial^{2} C / \partial Y^{2}\right)_{\theta}
$$

ここで

$$
d \phi(\theta) / d \theta=r_{0} /\left\{\beta(\theta)[\Delta(\theta)]^{3}\right\}
$$

とおくと(44)式はつぎのように変形できる16)

$$
Y(\partial C / \partial \phi)_{Y}=D\left(\partial^{2} C / \partial Y^{2}\right)_{\phi}
$$

さらに変数 $s=Y / \phi^{1 / 3}$ を導入すると上式はつぎの常微分 方程式に

$$
d^{2} C / d s^{2}+\left[s^{2} /(3 D)\right] d C / d s=0
$$


境界条件(38)は

$$
s=0: C=C_{0}, \quad s=\infty: C=0
$$

となつて簡単に解が得られる. その結果次式を得る.

$$
\left(\frac{\partial C}{\partial y}\right)_{y=0}=-\frac{1}{\phi^{1 / 3} J}\left(\frac{d C}{d s}\right)_{s=0}=-\frac{C_{0}}{\Gamma(1 / 3) d}\left(\frac{3}{\phi D}\right)^{1 / 3}
$$

局所物質移動係数は(43)，(45)，(49)式を用いてつぎの ようになる。

$$
\begin{aligned}
& k_{f \theta}=-\left(D / C_{0}\right)(\partial C / \partial y)_{y=0} \\
& =\frac{3^{1 / 3}}{\Gamma(1 / 3)} \frac{D^{2 / 3}}{r_{0}^{1 / 3}} \beta^{1 / 2} \sin ^{1 / 2} \theta\left[\int_{0}^{\theta} \beta^{1 / 2} \sin ^{3 / 2} \theta d \theta\right]^{-1 / 3}
\end{aligned}
$$

したがつて局所シャーウッド数はつぎのように表わせ る.

$$
S h_{\theta} \equiv=\frac{3 G(\theta)}{\sqrt{2} \Gamma(1 / 3)} \frac{S c^{1 / 3}}{\nu}\left(\frac{r_{0} a \omega}{\nu}\right)^{1 / 2}\left(\frac{a}{r_{0}}\right)^{1 / 6}
$$

ただし

$$
G(\theta)=(\sin 2 \theta \sin \theta)^{1 / 2}\left[\int_{0}^{\theta} \sin ^{1 / 2} 2 \theta \sin ^{3 / 2} \theta d \theta\right]^{-1 / 3}
$$

総括物質移動係数は $k_{f \theta}$ との間に

$$
k_{f}=\int_{0}^{\pi / 2} 2 \pi r_{0}^{2} k_{f \theta} \sin \theta d \theta / \int_{0}^{\pi / 2} 2 \pi r_{0}^{2} \sin \theta d \theta \cdots
$$

の関係があるので総括シャーウッド数はつぎのようにな る.

$$
\begin{aligned}
S h & =\frac{3 I S c^{1 / 3}}{\sqrt{2} \Gamma(1 / 3)}\left(\frac{r_{0} a \omega}{\nu}\right)^{1 / 2}\left(\frac{a}{r_{0}}\right)^{1 / 6} \\
\text { ここで } & \\
I & =\int_{0}^{\pi / 2} G(\theta) \sin \theta d \theta \ldots \ldots \ldots \ldots \ldots \ldots \ldots \ldots \ldots \ldots
\end{aligned}
$$

\section{2 解析結果のまとめ}

主流の定常速度を $U_{\infty}$ とすると，(40)式の $\beta$ 添添記し た各場に対してつぎのように表わせる.

定常流れ

$$
\beta=\left\{\begin{array}{lr}
f_{c}(\theta) \sqrt{2 U_{\infty}^{3} /\left(r_{0} \nu\right)} & (\text { 円柱 })^{6)} \\
f_{s}(\theta) \sqrt{3 U_{\infty}{ }^{3} /\left(r_{0} \nu\right)} & {\text { (球 })^{16)}}^{16}
\end{array}\right.
$$

\section{変動流れ}

$$
\beta=a^{2} \omega^{3 / 2} \sin 2 \theta /\left(r_{0} \sqrt{2 \nu}\right) \quad \text { (円柱) }
$$

脈動流れ

$$
\beta=\left\{\begin{array}{l}
f_{c}(\theta) \sqrt{2 U_{\infty}^{3} /\left(r_{0} \nu\right)} \\
\quad+a^{2} \omega^{3 / 2} \sin 2 \theta /\left(r_{0} \sqrt{2 \nu}\right) \text { (円柱) } \\
f_{\mathrm{s}}(\theta) \sqrt{3 U_{\infty}^{3} /\left(r_{0} \nu\right)} \\
\quad+9 a^{2} \omega^{3 / 2} \sin 2 \theta /\left(2^{9 / 2} r_{0} \nu^{1 / 2}\right) \text { (球) }
\end{array}\right.
$$

ただし脈動流れの場合, 定常流れと变動流れの重ね合わ せによつて(58)式のように表わせるものと考えた。上の 式の中で $f_{c}(\theta), f_{s}(\theta)$ は, 前岐点からはく離点までの
範囲の物体のまわりの定常流れに対して境界層理諭より 毷かれた関数で，(64)式に示してある.さて上記の各場 合に対して，3.1 節に示した解析方法が同じように適用 できるが，(55)式の積分範囲は，変動流れ以外の場合に は注意を要する.すなわち定常流れの場合，はく離点 $\theta_{s}$ から $\theta=\pi$ までは死水域で流れがないものとして取り扱 い, 脈動流れの場合には，(58)式において $\beta=0$ となる 点 $\theta=\theta_{s}^{\prime}$ （脈動流れの場合の時閒平均のはく朔点）が存 在するため，積分範囲を

$$
0 \leqq \theta \leqq \theta_{s}^{\prime}, \quad \theta_{s}^{\prime} \leqq \theta \leqq \theta_{s}, \quad \theta_{s} \leqq \theta \leqq \pi
$$

に分けて実施しなければならない。

けつきよく, 円柱と球の定常，变動および脈動流れの 場合について整理すると，つぎのようになる

定常・脈動流れ

$$
\begin{aligned}
& \left.\begin{array}{l}
S h_{\theta} \\
S h
\end{array}\right\}=C_{1}\left\{\begin{array}{c}
G(\theta) \\
I\left(\theta_{1}\right) / J\left(\theta_{2}\right)
\end{array}\right\} S c^{1 / 3} R e_{p}^{1 / 2}, \\
& C_{1}=\left\{\begin{array}{lr}
31 / 32^{2 / 3} / \Gamma(1 / 3) & \text { (円柱) } \\
\sqrt{6} / \Gamma(1 / 3) & \text { (球) }
\end{array}\right.
\end{aligned}
$$

変動流れ

$$
\begin{aligned}
& \left.\begin{array}{l}
S h_{\theta} \\
S h
\end{array}\right\}=C_{2}\left\{\begin{array}{c}
G(\theta) \\
I\left(\theta_{1}\right) / J\left(\theta_{2}\right)
\end{array}\right\} S c^{1 / 3}\left(\frac{r_{0} a \omega}{\nu}\right)^{1 / 2}\left(\frac{a}{r_{0}}\right)^{1 / 6}, \\
& C_{2}=\left\{\begin{array}{lr}
31 / 32^{5 / 6} / \Gamma(1 / 3) & \text { (円柱) } \\
3 /[\sqrt{2} \Gamma(1 / 3)] & \text { (球) }
\end{array}\right. \\
& J\left(\theta_{2}\right)= \begin{cases}\theta_{2} & \text { (円柱 } \\
\int_{0}^{\theta_{2}} \sin \theta d \theta & \text { (球) }\end{cases}
\end{aligned}
$$

ここで局所分布を与える関数 $G(\theta)$ は

$$
G(\theta)=\left\{\begin{array}{l}
F(\theta)^{1 / 2}\left[\int_{0}^{\theta} F(\theta)^{1 / 2} d \theta\right]^{-1 / 3} \quad(\text { 円柱) } \\
{[F(\theta) \sin \theta]^{1 / 2}\left[\int_{0}^{\theta} F(\theta)^{1 / 2} \sin ^{3 / 2} \theta d \theta\right]^{-1 / 3}}
\end{array}\right.
$$

また総括值 $S h$ を与える積分 $I\left(\theta_{1}\right)$ は

$$
I\left(\theta_{\mathbf{1}}\right)=\left\{\begin{array}{ll}
\int_{0}^{\theta}{ }^{1} G(\theta) d \theta & \text { (円柱) } \\
\int_{0}^{\theta}{ }^{1} G(\theta) \sin \theta d \theta & \text { (球) }
\end{array} \ldots\right.
$$

である・ただし

定常流れ

$$
\begin{aligned}
& F(\theta)=\left\{\begin{aligned}
f_{c}(\theta) & =2.4652 \theta-0.9659 \theta^{3}+0.1032 \theta^{5} \\
& -0.00647 \theta^{7}+0.0000154 \theta^{9} \\
& -0.0000407 \theta^{11}+\cdots(\text { 円柱 })^{6)} \cdots(64) \\
f_{s}(\theta) & =1.3916 \theta-0.5402 \theta^{3} \\
& +0.0585 \theta^{5}-0.00363 \theta^{7}+\cdots \text { (球 }^{6) 15)}
\end{aligned}\right. \\
& \theta_{2}=\pi, \quad \theta_{1}=\theta_{s}=108.8^{\circ} \text { (円柱) }, 109.6^{\circ} \text { (球) }
\end{aligned}
$$

変動流れ

$F(\theta)=\sin 2 \theta, \theta_{1}=\theta_{2}=\pi / 2$ (队柱, 球)

脈動流れ

$$
F(\theta)= \begin{cases}f_{c}(\theta)+(z / 2) \sin 2 \theta \quad \text { (住) } \\ f_{s}(\theta)+(3 \sqrt{6} / 32) z \sin 2 \theta \text { (球) }\end{cases}
$$




$$
z=\left(a \omega / U_{\infty}\right)^{3 / 2}\left(a / r_{0}\right)^{1 / 2}
$$

この無次元変数 $z$ の第 1 項 $\left(a \omega / U_{\infty}\right)$ は変動流れの代表 速度 $a \omega$ と定常流れのそれ $U_{\infty}$ の比, 第 2 項 $\left(a / r_{0}\right)$ は 無次元振幅である. 北浦ら ${ }^{3)}$ は半理論的な考察から振動 示数（变動圧力と粘性力の比を北浦らはこのように呼え

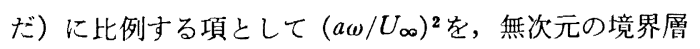
厚みに比例する項として $\sqrt{U_{\infty} /\left(r_{0} \omega\right)}$ を導き, 両者の積 を半理論的な実験式の中へと導入しているが，この積は 上記 $z$ と一致する.

なお球の場合には，流体が静止している時 $S h=2$ で あり，流れとは独立であるのでシャーウッド数にこの值 が加わる17).

\section{3 .3 計算結果と考察}

前節の解析結果に基づいて, 定常, 変動および脈動流 れにおける円柱と球からの局所ならびに総括物質移動係 数を求めた（62)式および(63)式の積分は $0.5^{\circ}$ きざみ でシンプソンの公式によつて数值計算しだが，たとえば あとの(70)式に示してある変動流れにおける円柱の場合 の係数 1.03 は，本計算ではくわしくは 1.033 とな り, JAMESON ${ }^{16) 18)}$ がベータ関数を用いて解析的に求めた 值 1.032 とよく一致したことから，精度は十分であるこ 思われる.

\section{$3 \cdot 3 \cdot 1$ 局所物質移動分布}

定常, 変動および脈動流れの場合の球面上の局所的な 物質移動分布の計算例を Fig. 4 に示寸. 上半球 $\left(0^{\circ} \leqq \theta\right.$ $\left.\leqq 90^{\circ}\right)$ では脈動流れにおける $S h_{\theta}$ は他の場合よりも大 きいが，三者とも前岐点 $\left(\theta=0^{\circ}\right)$ で最大值をとり， $\theta$

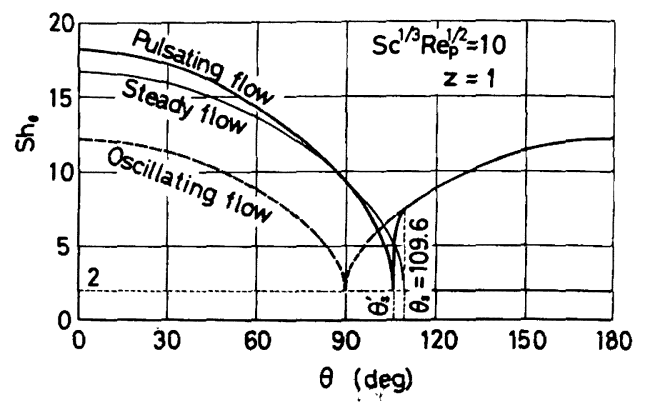

Fig. 4. Local variation of mass transfer around a sphere under steady, oscillating and pulsating flow.

が大きくなるにつれてなだらかに減少している．定常， 変動および脈動流れにおける $S h_{\theta}$ はそれぞれ $\theta=\theta_{s}, 90^{\circ}$ および $\theta_{s}^{\prime}\left(90^{\circ}<\theta_{s}^{\prime}<\theta_{s}=109.6^{\circ}\right.$ の範囲にあり， $z$ に依

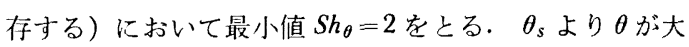
きくなると，变動流れと脈動流れにおける $S h_{\theta}$ は，全

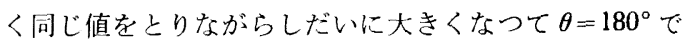
極大となるが，定常流れの場合には一定值 $S h_{\theta}=2$ をと る.なお円柱の場合にも, はく䜅点の位置が $\theta_{s}=108.8^{\circ}$, 最小值が $S h_{\theta}=0$ となることを除けば，球の場合と同様 な傾向をもつ分布が得られる.

このような局所物質移動分布の測定例としては, 定常

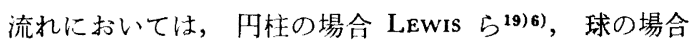
FrössLing ${ }^{20)}$, LiNTON $5^{21)}$, GiBerT $5^{22)}$, 脈動流れに おいては円柱の場合小保方ら ${ }^{23)}$, LEBOUCHE $5^{24)}$ の報告 があり，Fig. 4 の分布と定性的には一致している.ただ

Table 1. Summary of heat and mass transfer from a circular cylinder in steady flow.

\begin{tabular}{|c|c|c|c|c|c|}
\hline Author & Year & Remarks & Formulae & \multicolumn{2}{|c|}{ Applicable range } \\
\hline \multirow{2}{*}{ ULSAMER ${ }^{27)}$} & \multirow{2}{*}{1932} & \multirow{2}{*}{ Heat-transfer experiments } & $N u=0.91 P r^{0.31} \operatorname{Re}_{p}^{0.385}$ & $0.1 \leqq R e_{p} \leqq 50$ & \multirow{2}{*}{$0.7<\operatorname{Pr}<530$} \\
\hline & & & $N u=0.60 \operatorname{Pr}^{0.31} \operatorname{Re}_{p^{0.5}}$ & $50 \leqq R e_{p} \leqq 10^{4}$ & \\
\hline KRAMERS ${ }^{28)}$ & 1946 & $\begin{array}{l}\text { Heat-transfer experiments } \\
\text { reported previously } 27 \text { ) }\end{array}$ & $\begin{aligned} N u= & 0.42 \operatorname{Pr}^{0.20} \\
& +0.57 \operatorname{Pr}^{0.33} \operatorname{Re}_{p}^{0.50}\end{aligned}$ & \multicolumn{2}{|c|}{$0.1 \leqq R e_{p} \leqq 10^{4}, 0.7<\operatorname{Pr}<530$} \\
\hline $\begin{array}{l}\text { Douglas \& } \\
\text { CHuRCHILL }\end{array}$ & 1956 & $\begin{array}{l}\text { Heat-transfer experiments } \\
\text { reported previously }\end{array}$ & $\begin{aligned} N u= & 0.46 R e_{p}^{1 / 2} \\
& +0.00128 R e_{p}\end{aligned}$ & \multicolumn{2}{|c|}{$R e_{p} \geqq 500, \operatorname{Pr}=0.72$} \\
\hline FRIEDLANDER $^{30)}$ & 1957 & $\begin{array}{l}\text { Analysis based on } \\
\text { boundary-layer theory }\end{array}$ & $S h=0.557 S c^{1 / 3} \operatorname{Re}_{p^{1 / 3}}$ & \multicolumn{2}{|c|}{$R e_{p} \approx 0.1, S c \gg 1$} \\
\hline $\begin{array}{l}\text { KISER \& } \\
\left.\text { HORLSCHER }^{31}\right)\end{array}$ & 1957 & Mass-transfer experiments & $S h=0.211 S c^{1 / 3} R e p^{0.57}$ & \multicolumn{2}{|c|}{$5000<R e_{p}<70000$} \\
\hline GRAFTON ${ }^{25)}$ & 1963 & $\begin{array}{l}\text { Analysis based on } \\
\text { boundary-layer theory }\end{array}$ & $S h=0.90 S c^{1 / 3} \operatorname{Re}_{p}{ }^{1 / 2}$ & \multicolumn{2}{|c|}{$R e_{p}<6 \times 10^{6}, S c \gg 1$} \\
\hline RICHARDSON ${ }^{32)}$ & 1963 & $\begin{array}{l}\text { Heat-transfer experiments } \\
\text { reported previously }\end{array}$ & $\begin{aligned} N u= & 0.46 R e_{p}^{1 / 2} \\
& +0.0705 \operatorname{Re}_{p}{ }^{2 / 3}\end{aligned}$ & \multicolumn{2}{|c|}{$10^{2} \leqq R e_{p} \leqq 10^{5}, \operatorname{Pr}=0.72$} \\
\hline
\end{tabular}

$N u, \operatorname{Pr}:$ Nusselt and Prandtl-number for heat transfer corresponding to $S h$ and $S c$ for mass transfer, respectively. 
Table 2. Summary of heat and mass transfer from a circular cylinder in oscillating flow.

\begin{tabular}{|c|c|c|c|c|}
\hline Author & Year & Remarks & Formulae & Applicable range \\
\hline $\begin{array}{c}\text { DeAver, et al. } \\
\text { 33) }\end{array}$ & 1962 & $\begin{array}{l}\text { Heat-transfer experiments } \\
\quad \text { (vibrating cylinder) }\end{array}$ & $N u=0.35 \operatorname{Pr}^{0.3}+0.38 \operatorname{Pr}^{0.3}\left(\frac{r_{0} a \omega}{\nu}\right)^{0.52}$ & $\begin{array}{l}0.27 \leqq f \leqq 4.4 \mathrm{~Hz} \\
0.25 \leqq a \leqq 7.0 \mathrm{~cm} \\
\operatorname{Pr}=7.2\end{array}$ \\
\hline JAMESON $^{16)}$ & 1964 & $\begin{array}{l}\text { Analysis based on } \\
\text { boundary-layer theory }\end{array}$ & $S h=1.03 S c^{1 / 3}\left(\frac{r_{0} a \omega}{\nu}\right)^{1 / 2}\left(\frac{a}{r_{0}}\right)^{1 / 6}$ & $a / r_{0} \ll 1, S c \gg 1$ \\
\hline \multirow{3}{*}{ RICHARDSON ${ }^{34)}$} & \multirow{3}{*}{1967} & \multirow{3}{*}{$\begin{array}{l}\text { Analysis based on } \\
\text { boundary-layer theory }\end{array}$} & $\begin{aligned} N u= & 1.76 \overline{P^{1 / 2}\left(a^{2} \omega / \nu\right)^{1 / 2} /} \\
& \left\{1+0.83\left(a / r_{0}\right) \operatorname{Pr}^{1 / 2}\right\}\end{aligned}$ & $\operatorname{Pr} \ll 1$ \\
\hline & & & $N u=1.62 \operatorname{Pr}^{1 / 3}\left(\frac{r_{0} a \omega}{\nu}\right)^{1 / 2}\left(\frac{a}{r_{0}}\right)^{1 / 6}$ & $a / r_{0} \ll 1$ \\
\hline & & & $N u=0.969 \operatorname{Pr}^{1 / 3}\left(\frac{r_{0} a \omega}{\nu}\right)^{1 / 2}\left(\frac{a}{r_{0}}\right)^{1 / 6}$ & $P r \approx 1$ \\
\hline $\begin{array}{l}\text { SUGANO \& } \\
\text { RATKOWSKY }\end{array}$ & 1968 & $\begin{array}{l}\text { Mass-transfer experiments } \\
\text { (vibrating cylinder) }\end{array}$ & $\begin{array}{l}S h=1.03 S c^{1 / 3}\left(\frac{r_{0} a \omega}{\nu}\right)^{1 / 2}\left(\frac{a}{r_{0}}\right)^{1 / 6} \\
\text { or } \\
S h=0.276 S c^{1 / 3}\left(\frac{r_{0} a \omega}{\nu}\right)^{0.633}\left(\frac{a}{r_{0}}\right)^{0.243}\end{array}$ & $\begin{array}{l}1.6 \leqq f \leqq 116 \mathrm{~Hz} \\
0.2 \leqq a / r_{0} \leqq 5.7 \\
1.9 \leqq S c \leqq 3.23 \times 10^{7}\end{array}$ \\
\hline \multirow{4}{*}{ DAVIDSON $^{36)}$} & \multirow{4}{*}{973} & \multirow{4}{*}{$\begin{array}{l}\text { Method of matched as- } \\
\text { ymptotic expansions and } \\
\text { approximate method based } \\
\text { on an integrated form of } \\
\text { momentum and energy } \\
\text { equations }\end{array}$} & $N u=1.76 \operatorname{Pr}^{1 / 2}\left(a^{2} \omega / \nu\right)^{1 / 2}-2 / \pi$ & $a^{2} \omega / \nu \ll 1, \quad \operatorname{Pra}^{2} \omega / \nu \gg 1$ \\
\hline & & & $N u=\left(1.76 \operatorname{Pr}^{1 / 2}-0.26\right)\left(\frac{a^{2} \omega}{\nu}\right)^{1 / 2}$ & $a^{2} \omega / \nu \gg 1, \operatorname{Pr} \gg 1$ \\
\hline & & & $N u=\left(2.71 P r-5.51 P r^{2}\right)\left(\frac{a^{2} \omega}{\nu}\right)^{1 / 2}$ & $a^{2} \omega / \nu \gg 1, \quad \operatorname{Pr} \ll 1$ \\
\hline & & & $\begin{aligned} N u= & \left\{1.30 \operatorname{Pr}^{1 / 3}\left(r_{0} / a\right)^{1 / 3}\right. \\
& \left.-0.30 r_{0} / a\right\}\left(a^{2} \omega / \nu\right)^{1 / 2}\end{aligned}$ & $\begin{array}{l}a^{2} \omega / \nu \approx 1 \\
\operatorname{Pr}\left(a / r_{0}\right)^{2} \gg 1\end{array}$ \\
\hline
\end{tabular}

Table 3. Summary of heat and mass transfer from a sphere in oscillating flow. $S h=B_{1}+B_{2} S_{C}{ }^{1 / 3}\left(r_{0} a \omega / \nu\right)^{1 / 2}$

\begin{tabular}{|c|c|c|c|c|c|}
\hline Author & Year & Remarks & $B_{1}$ & $\mathrm{~B}_{2}$ & Applicable range \\
\hline $\begin{array}{l}\text { NoORDSIJ } \& \\
\text { RotTE }\end{array}$ & 1967 & $\begin{array}{l}\text { Mass-transfer experiments } \\
\text { (vibrating sphere in a fluid } \\
\text { at rest) }\end{array}$ & 2 & 0.135 & $\begin{array}{l}2.5 \leqq f \leqq 35 \mathrm{~Hz}, \quad 500<S c<2000 \\
0.075 \leqq a \leqq 0.1575 \mathrm{~cm}\end{array}$ \\
\hline MoRI, et al. ${ }^{37)}$ & 1969 & $\begin{array}{l}\text { Analysis and heat- and } \\
\text { mass-transfer experiments } \\
\text { (under pulsating flow) }\end{array}$ & 2 & 0.595 & $\begin{array}{l}23 \leqq f \leqq 70 \mathrm{~Hz}, \quad\left|u_{\mathrm{os}}\right|<6 \mathrm{~m} / \mathrm{sec} \\
u>3 \mathrm{~m} / \mathrm{sec}, \quad 0.6<S c(P r)<1.6\end{array}$ \\
\hline Kitaura, et al.3) & 1969 & $\begin{array}{l}\text { Analysis based on } \\
\text { boundary-layer theory and } \\
\text { mass-transfer experiments } \\
\text { (vibrating sphere in steady } \\
\text { flow) }\end{array}$ & 0 & $0.53\left(a / r_{0}\right)^{1 / 6}$ & $\begin{array}{l}1 \leqq f \leqq 11 \mathrm{~Hz}, \quad 1 \leqq a \leqq 4 \mathrm{~cm} \\
40<R e_{p}<300, \quad S c=2.85\end{array}$ \\
\hline HARA, et al. ${ }^{38)}$ & 1971 & $\begin{array}{l}\text { Mass-transfer experiments } \\
\text { (under ultrasonic wave) }\end{array}$ & 0 & $10.1\left(a / r_{0}\right)^{1 / 6}$ & $2 \times 10^{5} \leqq f \leqq 2 \times 10^{6} \mathrm{~Hz}$ \\
\hline
\end{tabular}

$\left|u_{\mathrm{os}}\right|$ : Magnitude of oscillating velocity

これらの測定結果では, 定常流れの場合, レイノルズ数 $R e_{p}$ が大きくなると死水域内の流れがある程度大きくな つて, 物質移動量む $S h_{\theta}=0$ または 2 よりは大きくなつ てくる.このような傾向は, 球の場合については GRAFTON ${ }^{25)}$ ，IHMEら 26) の理論解析から得られた分布図にも 認められる。 また $R e_{p}$ が大きくなると，はく離点ある
いは物質移動最小点の位置が前岐点側へ侈動するが，こ のような傾向についても本解析の結果では表わせず，し たがつて本解析の適用範四は原則としては比較的低いレ イノルズ数域に限定されることになる.

\section{$3.3 \cdot 2$ 総括物質移動}

（1）定常流れの場合 
(59)，(61)〜 (64)式より定常流れの場合の総括物質移 動を表わす式はつぎのようになつた。

$$
S h= \begin{cases}0.615 S c^{1 / 3} R e_{p}^{1 / 2} & \text { (队柱) } \\ 2+0.654 S c^{1 / 3} \operatorname{Re}_{p}^{1 / 2} & \text { (球) }\end{cases}
$$

円柱の場合の従来のおもな解析結果, および実験結果を Table 1 に示したが，(67)式と同じような形に整理した 報告が多数見受けられる。 その中で GRAFTON25) の解析 結果とは係数が異なり，ULSAMER ${ }^{27)}$ の高レイノルズ数 における実験結果とは係数とSc 数の指数とがわげかに 異なる程度であるので, 本解析結果は, 種々の仮定に立 つた近似的な取り扱いにもかかわらず，かなり满足のい くものであると考无られる。

球の場合, 前報2)で従来の式

$$
S h=2+A S c^{1 / 3} \operatorname{Re}_{p}{ }^{1 / 2}
$$

におけるAの值を，箺験の際の $R e_{p}$ の範囲について整 理して，全体的には $R e_{p}$ 值とともに増大寸る傾向が認 められるが，中程度の $R e_{p}$ 值 $\left(0.1 \leqq R e_{p} \leqq 2000\right)$ では $A=0.55$ 程度が妥当であることを示した。 いま理論的に 導いた(68)式は(69)式と全く同じ関数形となり，係数值 もある程度近い。ただしはく離点以降の死水域内では流 れがないとしていることや速度成分 $v$ を無視しているこ とから，物質移動量を低婄評価していると思われるに もかかわらず，係数值は従来の実験結果よりも大きくな つている.したがつて保数值については再度実験的に検 討しておく必要があると考えられるが，この点について は次報で報告することにする。

（2）変動流れの場合

(60)〜 (63)，（65)式より变動流れの場合の総括物質移 動を表わす式はつぎのようになつた。

$$
S h=\left\{\begin{array}{c}
1.03 S c^{1 / 3}\left(r_{0} a \omega / \nu\right)^{1 / 2}\left(a / r_{0}\right)^{1 / 6} \text { (円柱) } \cdots(70) \\
2+0.917 S c^{1 / 3}\left(r_{0} a \omega / \nu\right)^{1 / 2}\left(a / r_{0}\right)^{1 / 6}(\text { 球 }) \cdots(71)
\end{array}\right.
$$

さて, 以下では, 自然対流の影響が問題とならない条件 下（変動の周波数あるいは振幅が比較的大きい場合）に おける従来のおもな結果との比較を行なうことにする。 まず円柱の場合については Table 2 にまとめたとおり である・前にも述べたとおり JAMESON ${ }^{16)}$ の解析結果と は，途中の積分方法が異なるだけで，最終結果は全く同 一である. Sugano ら 18) の実験結果は，JAMESON の式 でもよく関係づけられるが，表中の式のようにも表わせ ると述べている. RICHARDSON ${ }^{34)}$ のP Pr 1 における解 析結果は，(70)式と関数形が同じであり，係数值は従来 の実験結果と合致するように決定されている。 DAVIDSON ${ }^{35)}$ のかなり锺密な解析など, 他の研究もいくつか見 られるが，上述の点から一応本解析結果はかなり満足の いくものであると考元らる.
つぎに球の場合については前報1)でも一部述べたが， $S h=B_{1}+B_{2} S c^{1 / 3}\left(r_{0} a \omega / \nu\right)^{1 / 2 \ldots}$

とおくと，Table 3 のように整理できる、 $a \omega \rightarrow 0$ の極 限では，理想的には前にも述べたように $S h=B_{1}=2$ と

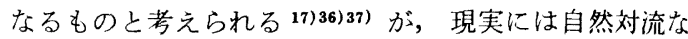
どの影響も生じうるので $B_{1}=0$ としてしまつている報 告338) もある. 交た $B_{2}$ については単に定数とするもの 36) 37) と, 無次元振幅の項 $\left(a / r_{0}\right)^{1 / 6}$ には定数が掛つた もの ${ }^{3338)}$ とがある. 前二者】(NOORDSIJ ら ${ }^{36)}$, MORI

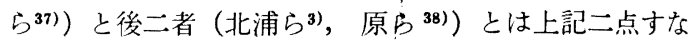
わち $B_{1}, B_{2}$ の值の取り扱い方が片手落ちであるが, (71)式は $B_{1}, B_{2}$ ともに敞密な形になつており， $B_{2}$ の中 の係数値 0.917 は，種々の仮定に立つた近似的な理論か ら得られた割には，满足のいく程度の值であるただ゙過 去の報告数も少ないため，さらに実験的な検討をする必 要があると考えられる.

(3) 脈動流れの場合

(66)式に示すとおり脈動流れの場合のシャーウッド数 は $z$ の関数で Fig. 5 に示すようになる.すなわち, 円 柱の場合球の場合ともに $z \rightarrow 0$ では定常流れの場合の 関係，(67)および(68)式， $z \rightarrow \infty$ では変動流れの場合の 関係，(70)掞よび(71)式にそれぞれ漸近する。そこで近 似式として

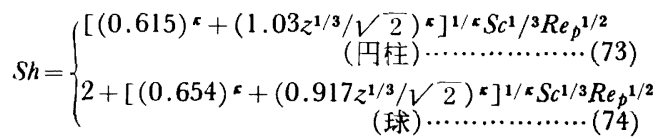

とおきハの最適値を検討した。すなわち(73)，(74)式

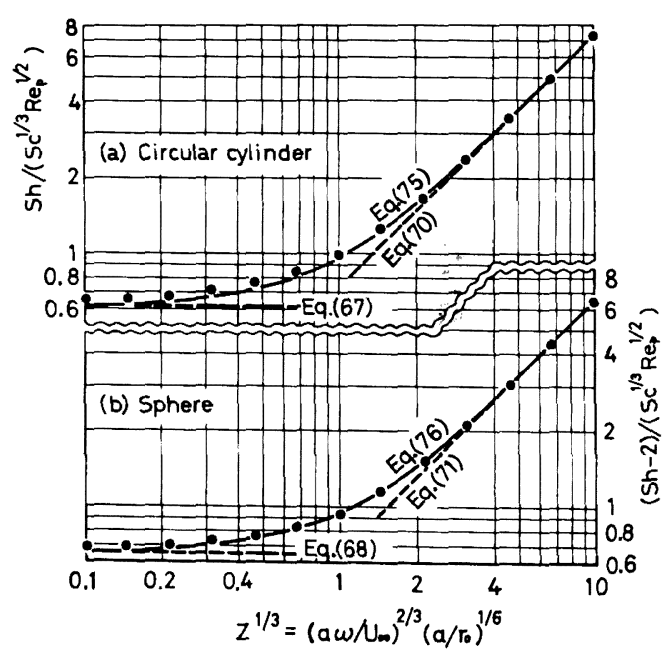

Fig. 5. Overall mass transfer under pulsating flow. 


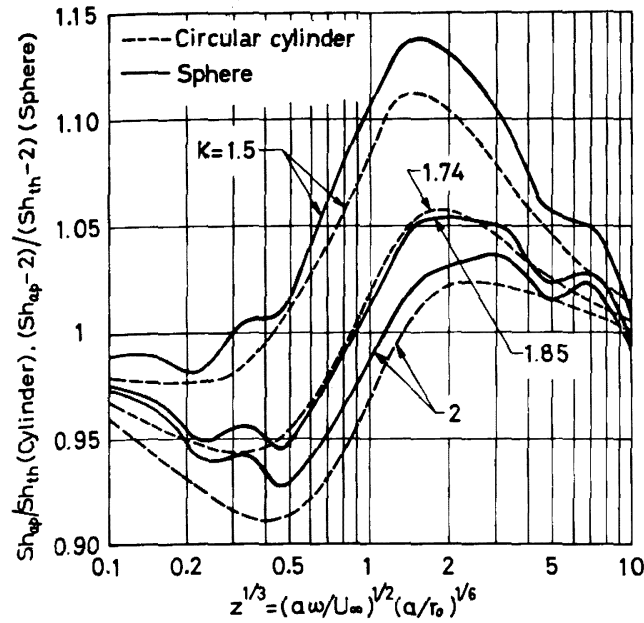

Fig. 6. Comparison of approximate expression for mass transfer under pulsating flow $S h_{a p}^{\prime}$ with theoretical value $S h_{t h}$.

において に種々の值を与えて算出した近似值 $S h_{a p}$ と (59)式から数値積分により求めた理論值 $S h_{t h}$ との比較 を行なうため, 円柱の場合 $S h_{a p} / S h_{t h}$, 球の場合 $\left(S h_{a p}\right.$ $-2) /\left(S h_{t h}-2\right)$ を縦軸にとり， $z^{1 / 3}$ に対して描くと Fig. 6 のようになるにの有効数字三桁までの範囲で調べたと ころ, 図に示したようにるの值によつて近似の程度は異 なるが，円柱の場合 $\kappa=1.74$ 球の場合 $\kappa=1.85$ とす ると，士5.6\% 程度の誤差範囲内で理論値を近似でき る.したがつて脈動流れの場合には近似式として次式が 得られる (Fig. 5 参照).

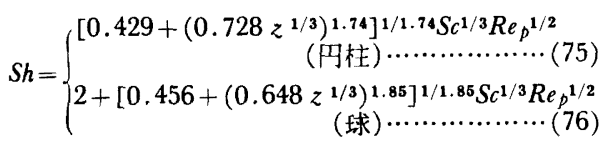

征来，主流に乱れがある場合についてはかなり報告39) されてきており，熱・物質移動を促進することが確かめ られているが，脈動流れを扱つた研究は非常に少ない。 小保方ら ${ }^{23)}$ は円柱のまわりの脈動流れと熱伝達とを数值 計算によつてかなり豃密に解析しているが，関係式を導 くまでには至つていない. MORI ら ${ }^{37)}$ は大振幅の脈動流 中の球からの熱・物質移動を理諭々実験の両面から解析 しており，変動支配域においては Table 3 にすでに示 したとおり簡潔な関倸式を得ているが，脈動流れにおい ては実験的に評俩しなければならないパラメータを含む 非常に入り組んだ式しか示していない. 北浦ら

$$
\begin{aligned}
S h & =\left[\left(2+0.55 S c^{1 / 3} R e_{p^{1 / 2}}\right)^{3}\right. \\
& \left.+\left(0.375 z^{1 / 3} S c^{1 / 3} R e_{p^{1 / 2}}\right)^{3}\right]^{1 / 3}
\end{aligned}
$$

については前報1) で詳しく述べ，脈動還元反応の解析
に用いたが，定常流中で球が振動する実験から㐿数值 (0.375) が決定されたことなどから，脈動流れの場にそ のまま適用できるかどうかはまだ十分明らかではない，

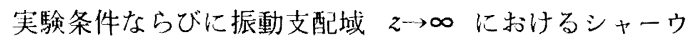
ッド数は Table 3 に示したとおりである. (76) 式と （77）式の形の上での大きな違いは流れがない場合の值 “ 2 ”の取り扱い方であるが，この点を除けば式の形は全 く同じで，定数值 $(0.654$ と 0.55), 係数值 (0.648 と 0.375）および指数值（1.85 と 3 ）が異なるだけであ る.したがつて定常流れおよび变動流れの場合の結果と も考え合わせると，(76)式はある程度は满足のいく結果 であるが，さらには実験的な検討をしておく必要がある と考えられる.

\section{4. 結論}

（1）静止流体中で微小・調和振動する物体のまわり の速度の解を境界層理論に基ゔいて導き，円柱と球の場 合の定常な二次流れを図示した（Fig. 2，3).

（2）物質収支の式に，上の結果と定常流れの場の往 来の解析結果とを用いて, 定常, 変動および脈動流れに おける円柱と球からの局所ならびに総括物質移動を表わ す一般式 [(59)〜(66)式]を導いた。

（3）上記一般式の中に含まれる積分を数值計算し て，局所物質移動分布図（Fig. 4)，総括物質移動式 [(67)，(68)，(70)，(71)，(75)，(76) 式]を三とおり の流れについて示し，従来の理論あるいは実䠼結果と比 較検討したところ，近似的な解析結果ではあるがかなり 満足のいくものであることがわかつた.

おわりに本研究に協力した増山嘉一君（現在，久保田 鉄工(株)勤務）に感謝の意を表する。

\section{記 号}

$a$ : 振幅 $(\mathrm{cm})$

$C:$ ガス濃度 $\left(\mathrm{g} / \mathrm{cm}^{3}\right)$

$C_{0}:$ 物体表面のガス濃度 $\left(\mathrm{g} / \mathrm{cm}^{3}\right)$

$D$ : 桩散倸数 $\left(\mathrm{cm}^{2} / \mathrm{sec}\right)$

$k_{f}:$ 総括物質移動係数 $(\mathrm{cm} / \mathrm{sec})$

$k_{f \theta}$ : 局所物質移動係数 $(\mathrm{cm} / \mathrm{sec})$

$p:$ 压力 $\left[\mathrm{g} /\left(\mathrm{cm} \cdot \mathrm{sec}^{2}\right)\right]$

$R e_{p}:$ イノルズ数 $\equiv 2 r_{0} U_{\infty} / \nu$ (-)

$r$ : 回転体の半径 [Fig. $1(\mathrm{~b})](\mathrm{cm})$

$r_{0}$ : 円柱または球の半径 $(\mathrm{cm})$

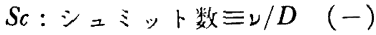

$S h$ : 総括シャ一ウッド数三 $2 r_{0} k_{f} / D \quad(-)$

$S h_{\theta}$ : 局所シャーウッド数 $\equiv 2 r_{0} k_{f \theta} / D(-)$

$t$ : 㭙間 ( $\mathrm{sec})$

$U$ : 境界㬄外部のポテンシャル流れ $(\mathrm{cm} / \mathrm{sec})$

$U_{0}$ : ポテンシャル流れの振幅 $[(6)$ 式 $](\mathrm{cm} / \mathrm{sec})$

$U_{\infty}:$ 主流の定常速度 $(\mathrm{cm} / \mathrm{sec})$ 


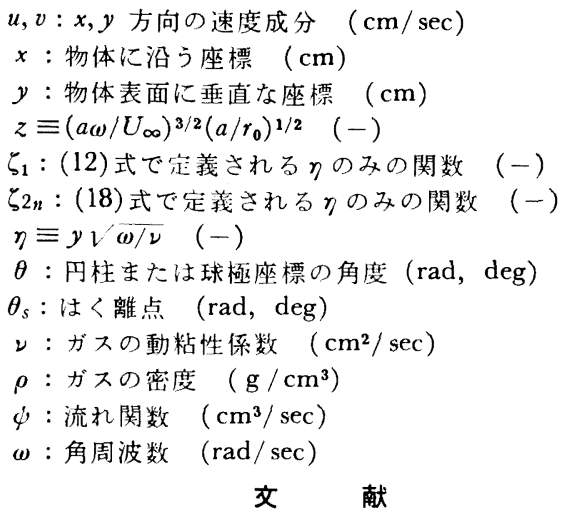

1) 近江宗一，碓井建夫：鉄と鋼，59（1973), p. 1902

2 ) 近江宗一, 碓井建夫：鉄と鋼，59(1973), p. 1888; $M$. Онмi and $T$. Usui: Trans. ISIJ, 16(1976), p. 77

3 ) 北浦嘉之, 田中久弥, 上田義一, 小島紀夫: 化学 工学, 33(1969), p. 175

4) H. Schlichting: Phys. Z., 33(1932), S 327

5 ) D. Roy: Z. Angew. Math. Phys., 12(1961), p. 363

6 ) H. Schlichting: Boundary-Layer Theory, (1968), p. 158, 226, 298, 391 [McGraw-Hill]

7 ) V. L. Shah: Trans. ASME, Ser. C, 92(1970), p. 661

8 ) $J$. Holtsmark, $I$. Johnsen, $T$. Sikkeland, and $S$. Skavlem: J. Acoustical Soc. America, 26 (1954), p. 26

9 ) $A$. Bertelsen, $A$. Svardal, and $S$. Tjøtta: J. Fluid Mech., 59(1973), p. 493

10) 堀栄一: 日本機械学会論交集, 27(1961), p. 1731

11) N. Riley: J. Fluid Mech., 68(1975), p. 806

12) 遠滕一夫, 平野晴望: 北海道大学工学部研究報 告, $60(1971)$, p. 111

13) H.-C. YEH and $W .-J$. YANG: Phys. Fluids, 8 (1965), p. 806

14) N. Riley: Quart. J. Mech. Applied Math., 19 (1966), p. 461

15) F. W. Scholkemeier: Arch. Math., 1 (1948/ 1949), p. 270

16) G. J. Jameson: Chem. Eng. Sci., 19(1964), p. 793

17) R. B. Bird, W. E. Stewart, and E. N. LightFOOT: Transport Phenomena, (1960), p. 303 [John Wiley \& Sons]

18) $Y$. Sugano and $D$. A. Ratkowsky: Chem. Eng. Sci., 23(1968), p. 707

19) J. S. Lewis: Int. J. Heat Mass Transfer, 14 (1971), p. 325

20) N. Frössling: Gerl. Beitr. Geophys., 52(1938), p. 170

21) $M$. Linton and $K$. L. Sutherland: Chem. Eng. Sci., 12(1960), p. 214

22) $H$. Gibert et $H$. Angelino: Chem. Eng. Sci., 28(1973), p. 855

23）小保方富夫, 阔島 厚, 谷田好通: 日本機械学会 笙演論交集，No. 760-5(1976)，p. 163

24) $M$. Lebouche et $M$. Martin: Int. J. Heat Mass Transfer, 18(1975), p. 1161

25) R. W. Grafton: Chem. Eng. Sci., 18(1963), p. 457

26) $F$. Ihme, $H$. Schmidt-Traub, und $H$. Brauer VDI-Berichte, Nr. 187(1972), S 84

27) J. Ulsamer: Forschung, 3(1932), S 94

28) H. Kramers: Physica, 12(1946), p. 61

29) $W . J . M$. Douglas and $S . W$. Churchill: Chem. Eng. Progress Symp. Ser., 52(1956), p. 23

30) S. $K$. Friedlander: AIChE J., 3(1957), p. 43

31) $K$. M. Kiser and $H$. E. Hoelscher: Indust. Eng. Chem., 49(1957), p. 970

32) P. D. Richardson: Chem. Eng. Sci., 18(1963), p. 149

33) F. $K$. Deaver, $W . R$. Penney, and $T . B . \mathrm{Je}-$ FFERSON: Trans. ASME, Ser. C, 84(1962), p. 251

34) P. D. Richardson: J. Fluid Mech., 30 (1967), p. 337

35) B. J. Davidson: Int. J. Heat Mass Transfer, 16(1973), p. 1703

36) $P$. Noordsij and $J$. $W$. Rotte: Chem. Eng. Sci., 22(1967), p. 1475

37) $Y$. Mori, $M$. Imabayashi, $K$. Hijikata, and Y. Yoshida: Int. J. Heat Mass Transfer, 12 (1969), p. 571

38) 原弘, 島田浩次, 遠藤一夫：化学工学, 35 (1971), p. 597

39) G. W. LOWERY and R. I. VACHON: Int. J. Heat Mass Transfer, 18(1975), p. 1229 